\title{
PENGARUH PEMBERIAN NECK CALLIET EXERCISE TERHADAP \\ PENURUNAN NYERI LEHER PADA PEGAWAI ADMINISTRASI DI UNIT PELAKSANA TEKNIS DAERAH PUSKESMAS HILIDUHO TAHUN 2020
}

\section{ISIDORUS JEHAMAN ${ }^{1}$, MARTHA PUTRI MENDROFA², SABIRIN BERAMPU ${ }^{3}$, SITI SARAH BINTANG ${ }^{4}$}

\author{
1,2,3,4 INSTITUT KESEHATAN MEDISTRA LUBUK PAKAM \\ JL. SUDIRMAN NO.38, KEL. LUBUK PAKAM PEKAN, KEC. LUBUK PAKAM, KAB. \\ DELI SERDANG, PROVINSI SUMATERA UTARA \\ e-mail : dorusman1976@gmail.com \\ DOI : $10.35451 / j k f . v 3 i 1.508$
}

\begin{abstract}
Neck pain is a collection of symptoms related to degenerative processes as well as those that are not related to degenerative processes such as poor positioning in job activity direct trauma or repetitive micro-trauma. In helping to reduce neck pain in patients, the treatment given is neck calliet exercise. To find out the influence of neck calliet exercise to decrease neck pain in administration. This research is a quantitative study, a pseudo-experimental quasi by using the one group pre-Test post-Test design, having a sample of 18 respondents with a total sampling technique. Data analysis obtained using $T$ Test paired sample test which obtained the mean result before the administration neck Calliet exercise is 5.50 with a standard deviation of 0.985 and the mean after giving neck calliet exercise is 3.44 with a standar deviation of 0.856 , which means there is a decrease in neck pain after given the neck calliet exercise with use $P$ value $=0.000(P<0.05)$. The result showed that the giving of neck calliet exercise was influential for the reduction of neck pain in administration. Conclusion: giving neck calliet exercise is very effective against the reduction of neck pain in administration. Suggestion: The patient must re-apply the instruction given by the physiotherapy at home.
\end{abstract}

Keywords: neck pain, neck calliet exercise

\section{PENDAhuluan}

Masalah kesehatan yang sering dirasakan pada bekerja adalah Muskuloskeletal Disorder (MSDs) dengan derajada keluhan mulai dari rasa ringan hingga rasa. Salah satu keluhan MSDs yang paling banyak dialami para pekerja khususnya pada orang dewasa adalah nyeri pada otot leher, Kondisi ini disebabkan karena beberapa faktor (Nadhifah dkk, 2019).
Hasil penelitian BLS (Bureau of Labour Statistics) Amerika bahwa terdapat 365.580 kasus MSDs untuk semua pekerja di Amerika Serikat (U.S Bureau of Labor Statistics, 2017).

Hasil Penelitian yang dilakukan pada pekerja industri jasa di Washington pada tahun 2002 hingga 2010 menyatakan bahwa keluhan muskuloskeletal akhibat pekerjaan paling banyak mengeluh sakit 
punggung dengan jumlah 24.000 orang, diikuti keluhan sakit pergelangan tangan, bahu, lutut, leher daerah siku (Howard et al, 2016).

Pada pekerja kantor yang duduk didepan komputer dengan durasi yang lama memiliki resiko tinggi terjadinya nyeri leher sebesar 95\%. Hal ini membuktikan bahwa orang yang menggunakan komputer selama lebih dari 5 jam perhari memiliki resiko nyeri pada otot leher (Riadho dan Wahyuddin, 2019).

Posisi tubuh pada saat menggunakan komputer cenderung tidak ergonomis seperti posisi komputer yang letaknya lebih tinggi atau lebih rendah dari posisi kepala sehingga poisi leher terangkat atau menunduk, serta posisi tubuh yang sering membungkuk. Posisi tersebut dapat menyebabkan keluhan musculoskeletal. Saat tubuh dalam posisi statis terjadi kontraksi terus menerus pada otot. Apa bila posisi tersebut menetap dengan jangka waktu yang lama dapat menyebabkan terjadinya kerusakan pada tendon otot (Prianthara dkk, 2014).

Keadaan tersebut mempoisisikan tubuh pada posisi statis sehingga dapat mengakibatkan gangguan pada muskuloskeletal. Posisi tubuh dalam keadaan statis menyebabkan kontraksi otot secara terus menerus. Adanya Perlengketan jaringan menyebabkan kurangnya asupan nutrisi dan oksigen sehingga menimbulkan ischemia. Hal tersebut akan mengakibatkan nyeri pada otot yang berkontraksi terutama pada daerah leher (Prianthara dkk, 2014). Nyeri leher dapat terjadi karena adanya tekanan pada tendon, otot, ligamen, gangguan tulang, atau gangguan pada leher. Selain itu nyeri leher dapat juga terjadinya adanya trauma hiperekstensi atau whisplash injury, overuse dengan posisi menunduk terlalu lama saat bekerja. Gejala yang ditimbulkan akibat nyeri pada leher adalah berupa ketegangan otot atau spasme di daerah leher yang mengakibatkan keterbatasan gerak leher sehingga fungsional leher akan terhambat (Trisnowiyanto 2017).

Gangguan kesehatan yang dialami para pekerja terjadi jika beban yang diterima berulang-ulang dan posisi statis dalam waktu yang lama maka dapat menyebabkan kerusakan pada jaringan otot, tendon, syaraf, persendian tulang kartilago, dan diskus (Devi et al., 2017). Nyeri leher merupakan gangguan yang sangat umum diperkirakan $70 \%$ populasi pernah mengalami nyeri leher. Nyeri leher merupakan kasus-kasus msukuloskeletal terbesar kedua setelah gangguan nyeri punggung bawah (lower back pain).

Nyeri leher merupakan gangguan musculoskeletal dan terjadi pada masyarakat modern. Sebuah studi menunjukkan bahwa prevalensi neyeri pada muskuloskeletal pada leher selama 1 (satu) tahun diperkirakan sebesar $40 \%$ dan prevalensinya lebih tinggi terjadi pada (Haryatno dan Kuntono, 2016).

Penelitian yang dilakukan pada pekerja kantor dengan menggunakan komputer diperoleh informasi angka prevalensi keluhan bahu mencapai $33 \%$. Penelitian sejenis yang dilakukan pada pekerja kantor dengan menggunakan computer di negara berkembang seperti Srilangka diperolah prevalensi keluhan sebesar gangguan pada leher mencapai $36,7 \%$ dan keluhan pada bahu/lengan mencapai $32 \%$. Prevalensi tertinggi ditemukan pada pekerja kantor dengan menggunakan komputer di Sudan, keluhan nyeri leher mencapai $64 \%$ dan keluhan bahu/lengan $41 \%$ (Silvia dkk, 2017). Gangguan kesehatan yang 
terjadi pada pekerja di Indonesia yag dilakukan pada 9.482 orang pekera di 12 kabupaten/Kota menunjukan angka tertinggi yaitu gangguan musculoskeletal sebesar, 23\%, disusul gangguan kardiovaskular $8 \%$, gangguan saraf $5 \%$, gangguan pernapasan $3 \%$, serta gangguan THT 1.5\%, (Sekaaram dan Ani, 2017).

Gangguan nyeri leher di indonesia setiap tahun terus bertambah mencapai $16,6 \%$ pada populasi orang dewasa yang mengeluhkan rasa tidak nyaman dibagian leher, bahkan sekitar 0,6\% nyeri leher berawal dari rasa tidak nyaman disekitar leher menjadi nyeri berat. Kejadian nyeri leher mengalami peningkatan dengan bertambahnya usia, dimana kejadian nyeri leher lebih sering mengenai laki-laki dengan perbandingan 2:1 (Juliastuti, 2017). Berdasarkan hasil survei studi pendahuluan di Unit Pelaksana Teknis Daerah Puskesmas Hiliduho diperoleh data penderita nyeri leher pada tahun 2020 sebanyak 18 orang (Juliastuti, 2017).

Peran fisioterapi dalam berbagai sarana layanan di Indonesia, telah diatur dalam Peraturan Menteri Kesehatan Republik Indonesia (PMK) Nomor 65 TAHUN 2015 Bab I, pasal 1 dan 2 tentang Pedoman Pelayanan Fisioterapi di Sarana Kesehatan. Peran Fisioterapi sebagaimana dijelaskan dalam PMK tersebut menjelaskan bahwa dalam menjalankan profesinya dapat meberikan pelayanan baik di rumah sakit pemerintah, rumah sakit swasta, rumah sakit khusus, Puskesmas maupun praktik mandiri Fisioterapi dengan memanfaatkan sumber daya yang ada seperti manual terapi, terapi Latihan, peralatan (elektroterapi dan mekanis) latihan peningkatan fungsi, dan komunikasi.

Intervensi fisioterapi yang dapat dilakukan untuk mengurangi nyeri leher meliputi ultrasound, Micro Wave Diathermy (MWD), massage, traksi, stretching, hold relax, myofacial release, terapi latihan, transcutaneous electrical nerve stimulation (TENS), dan terapi manipulasi. Menurut penelitian Nugraha, Antari, dan Saraswati 2019 tentang penerapan elektroterapi dan terapi latihan pada penderita mechanical neck pain dapat meningkatkan lingkup gerak sendi leher, sedangkan Penelitian Sunyiwara, Putri, Sabita 2019 tentang pengaruh pemberian myofascial release dengan hold relax dapat digunakan untuk mengatasi myiofascial pain otot upper trapezius.

Menurut penelitian Kuswardanin, Abidin dan Amin 2017 bahwa pemberian MWD, TENS, terapi Latihan dan terapi manipulasi dapat mengurangi nyeri, meningkatkan kekuatan otot ekstensor leher dan kemampuan aktivitas fungsional leher partisipan.

Metode lain yang dapat digunakan untuk mengurangi nyeri leher adalah neck calliet exercise. Intervensi ini memiliki banyak manfaat antara lain, mengurangi rasa nyeri, mengembalikan gerak sendi menjadi full ranges of motion (ROM), dan mengilangkan spasme (Kisner dan Colby, 2007 dalam Kusuma H dan Trisnowiyanto B, 2017) akan tetapi intervensi tersebut belum banyak dilakukan di klinik maupun rumah sakit sehingga peneliti tertarik untuk mengambil penelitian tentang "Pengaruh pemberian neck calliet exercise terhadap penurunan nyeri leher pada pegawai administrasi di Unit Pelaksana Teknis Daerah Puskesmas Hiliduho Tahun 2020".

\section{METODE PENELITIAN}

Penelitian ini dilaksanakan di Unit Pelaksana Teknis Daerah Puskesmas Hiliduho yang dilaksanakan pada bulan 
Desember 2019 sampai bulan Juli 2020. Jenis penelitian ini adalah penelitian kuantitatif, eksperimen semu (quasi experimental) dengan menggunakan rancangan one group pre-test post-test design dengan untuk mengetahui neck calliet exercise dapat menurunkan nyeri leher pada responden yang bekerja pada di Puskesmas Hiliduho Tahun 2020. Teknik pengambilan sampel dipakai dalam penelitian ini yaitu Total sampling yaitu pegawai administrasi di Puskesmas Hiliduho sebanyak 18 orang.

Dalam penelitian ini observasi dan pengukuran dilakukan sebelum dan sesudah intervensi neck calliet exercise terhadap skala nyeri pada kasus nyeri leher.Pengukuran nyeri pada penelitian ini menggunakan Verbal Anolog Scale (VAS). Data hasil pengukuran akandiuji dengan Paired Sample t-test.

Neck calliet exercise adalah terapi latihan yang menggunakan konsep isometrik denganmenahan resistensi maksimum dan diakhiri dengan relaksasi dan dilanjutkan denganperegangan. Tujuan dari latihan ini adalah untuk mengatasi kejang otot dan untuk mempertahankan atau meningkatkan kekuatan otot leher dalam resistensi leher statis dandinamis, mempertahankan gerakan sendi lebar dan fleksibilitas leher, dan mendapatkan postur yang benar dengan koreksi ketidakseimbangan otot (Kusuma dan Trisnowiyanto, 2017).

Prosedur pelaksanaan neck calliet exercise

a. Pemanasan:

1) Pasien dalam posisi duduk kemudian minta untuk miring kiri dan miring kanan masing-masing gerakan dihitung 8 kali.

2) Gerakan fleksi dan ekstensi kepala.

3) Gerakan roatasi servikal ke kanan dan ke kiri masing Gerakan dihitung 8 kali putaran.

b. Gerakan Inti:

1) Letakkan salah satu tangan terapis dibagian depan dahi kemudian pasien disuruh menggerakan kepalanya kearah fleksi dan tangan fisioterapi menahan Gerakan tersebut. Gerakan tersebut dilakukan selama 6 detik dan 10 kali pengulangan.

2) Letakan tangan fisioterapis pada kepala bagian belakang (Occipital), kemudian pasien diminta untuk melakukan gerakan ekstensi dan fisioterapis menahan gerakan tersebut selamat 6 detik dan 10 kali pengulangan

3) Letakkan tangan terapis di kepala bagian temporal sebelah kanan persis di atas telinga, kemudian pasien diminta untuk menggerakan kearah lateral fleksi kanan dan fisioterapi menahan gerakan tersebut selama 6 detik dan 10 kali pengulangan.

4) Letakkan tangan terapis di kepala bagian temporal sebelah kiri persis di atas telinga, kemudian pasien diminta untuk menggerakan kearah lateral fleksi kiri dan fisioterapi menahan gerakan tersebut selama 6 detik dan 10 kali pengulangan

5) Contract relax stretching, feksi kepala dan rotasi kiri dana kanan.

a. Penutup: Gerakan hampir sama dengan pemananasan.

1) Kepala menoleh ke kanan dan ke kiri dengan hitungan 8 kali.

2) Kepala di arah ke atas dan ke bawah

3) Kepala diputar dari arah kanan ke kiri dan sebaliknya sebanyak 8 kali putaran.

\section{Hasil penelitian}

3.1 Karakteristik responden umur Berdasarkan tabel 1, jumlah responden umur 23- 25 pada intervensi 
neck calliet exercise sebanyak 8 orang $(44,4 \%)$, sedangkan jumlah responden berdasarkan umur 26-29 pada intervensi neck calliet exercise adalah sebanyak 10 orang $(55,6 \%)$.

Tabel 1 Karakteristik Responden Umur.

\begin{tabular}{cccc}
\hline No & Umur & $\mathrm{n}$ & $\begin{array}{c}\text { Presentase } \\
(\%)\end{array}$ \\
\hline 1 & $23-25$ & 8 & $44,4 \%$ \\
2 & $26-29$ & 10 & $55,6 \%$ \\
\hline & Total & 18 & 100,0 \\
\hline
\end{tabular}

3.2 Karakteristik Responden jenis kelamin

Berdasarkan Tabel 2, jumlah responden berdasarkan jenis kelamin laki-laki pada intervensi neck calliet exercise adalah sebanyak 5 orang $(27,8 \%)$, dan jumlah responden berdasarkan jenis kelamin perempuan pada intervensi neck calliet exercise adalah sebanyak 13 orang $(72,2 \%)$.

Tabel 2. Karakteristik Responden Jenis Kelamin

\begin{tabular}{cccc}
\hline No & $\begin{array}{c}\text { Jenis } \\
\text { kelamin }\end{array}$ & $\mathrm{n}$ & $\begin{array}{c}\text { Presentase } \\
(\%)\end{array}$ \\
\hline 1 & Laki-laki & 5 & $27,8 \%$ \\
2 & Perempuan & 13 & $72,2 \%$ \\
\hline & Total & 18 & 100,0 \\
\hline
\end{tabular}

\subsection{Rerata hasil pengukuran nyeri VAS}

Hasil pengukuran nyeri dengan menggunakan VAS dapat diketahui bahwa hasil analisis rerata nyeri sebelum perlakuan neck calliet exercise pada pasien nyeri leher yaitu 5,50 dengan standart deviasi 0,985 dan standart error 0,232, sedangkan rerata nyeri sesudah perlakuan neck calliet exercise yaitu 3,44 dengan standart deviasi 0,856 dan standart error 0,202 (Tabel 3).

Tabel 3 Rerata nyeri sebelum dan sesudah perlakuan neck calliet exercise

\begin{tabular}{cccc}
\hline Nyeri & Mean & $\begin{array}{c}\text { Std. } \\
\text { Deviasi }\end{array}$ & $\begin{array}{c}\text { Std. } \\
\text { Error }\end{array}$ \\
\hline $\begin{array}{l}\text { Nyeri sebelum } \\
\text { perlakuan neck }\end{array}$ & 5,50 & 0,985 & 0,232 \\
\hline
\end{tabular}

\begin{tabular}{llll}
\hline calliet exercise & & & \\
\hline Nyeri sesudah & & & \\
perlakuan neck & 3,44 & 0,856 & 0,202 \\
calliet exercise & & & \\
\hline
\end{tabular}

3.4 Pengaruh pemberian neck calliet exercise

Berdasarkan hasil uji statistik diperoleh mean 2,056 dengan SD 0,725 dan $p$-value $<$ a $(0,000<0,05)$ maka dapat disimpulkan bahwa ada pengaruh pemberian neck calliet exercise terhadap penururan nyeri leher pegawai administrasi di Unit Pelaksana Teknis Daerah Puskesmas Hiliduho Tahun 2020 (Tabel 5).

Tabel 5 Selisih rerata nyeri sebelum dan sesudah perlakuan neck calliet exercise

\begin{tabular}{lllll}
\hline \multicolumn{1}{c}{ Nyeri } & Mean $\begin{array}{c}\text { Std. } \\
\text { Deviasi }\end{array}$ & $t$ & $\begin{array}{c}p- \\
\text { value }\end{array}$ \\
\hline $\begin{array}{l}\text { Nyeri sebelum } \\
\text { dan sesudah } \\
\begin{array}{l}\text { perlakuan neck } \\
\text { calliet exercise }\end{array}\end{array}$ & 2,056 & 0,725 & 12,023 & 0,000 \\
\hline
\end{tabular}

\section{PEMBAHASAN}

4.1 Karakteristik Responden

Berdasarkan Karakteristik, jenis kelamin dan faktor usia adalah salah satu penyebab terjadinya kasus muskuloskeletal. Menurut Binarfika et al., (2014) dan Tarwaka (2016) bahwa Usia merupakan salah satu faktor yang mempengaruhi gejala adanya keluhan $M S D s$, dan mulai dirasakan pada usia 20-40 tahun yang disebabkan oleh faktor degenerasi dan beban aktifitas yang dilakukan secara statis dan dinamis, sedangkan penelitian yang dilakukan oleh Yuniarti, dkk (2018) yang menyatakan bahwa wanita lebih dominan menderita myofascial trigger point syndrome otot upper trapezius dibanding lelaki. Kekuatan otot yang berbeda dimana wanita hanya sekitar dua pertiga dari kekuatan otot laki-laki sehingga daya tahan ototpada beban 
kerja laki-laki lebih tinggi dibanding wanita, selain itu dapat juga dipengaruhi karena faktor hormonal, dan faktor psikologis yang dapat mempengaruhi sensitifitas nyeri.

Nyeri leher pada pengguna komputer besarnya berkisar antara $60 \%-70 \%$ dan wanita lebih tinggi dibandingkan pria, karena kecenderungan wanita yang memiliki kekuatan otot yang lebih rendah dan perawakan yang lebih kecil (misalnya, lengan yang lebih pendek dan bahu yang sempit) menyebabkan mereka cenderung berpostur buruk saat melakukan aktivitas sehingga wanita lebih beresiko daripada laki-laki. (Haryatno, 2016).

4.2 Pengaruh neck calliet exercise terhadap penurunan nyeri leher

Dalam teori yang disampaikan oleh Cailliet (2014) bahwa neck calliet exercise dapat menurunkan nyeri dengan konsep post isometric relaxation. Kontraksi yang terjadi saat pemberian neck calliet exercise akan menstimulasi reseptor otot yaitu golgi tendon organ. Impuls yang diterima oleh golgi tendon organ akan diteruskan oleh saraf afferent menuju bagian dorsal dari spinal cord dan bertemu dengan inhibitor motor neuron. Hal ini dapat menghentikan impuls motor neuron efferent, sehingga dapat mencegah kontraksi yang lebih lanjut dan terjadilah relaksasi pada otot. Relaksasi yang terjadi pada otot dapat meningkatkan sirkulasi ke area yang mengalami nyeri, sehingga zatzat yang menimbulkan nyeri dapat dikeluarkan dari jaringan.

Penelitian Sari (2019) pemberian neck calliet exercise dapat memicu reaksi pada golgi tendon organ pada otot. Rangsangan sistem persayarafan afferent yang berasal dari golgi tendon masuk ke bagian dorsal medulla spinalis dan menginhibisi motor yang menyebabkan relaksasi pada otot dan penurunan nyeri. Penelitian Penelitian sejenis yang dilakukan oleh Sowmya, (2014), tentang pemberian latihan isometrik pada neck calliet digunakan sebagai teknik khusus dalam fasilitasi neuromuskuler proprioseptif untuk meningkatkan daya tahan dan memperkuat otot-otot dibagian yang lemah.

Latihan isometrik paling banyak efektif ketika individu dalam pelatihan rendah, karena manfaat latihan isometrik berkurang sebagai keadaan pelatihan meningkat.

\section{KESIMPULAN}

Hasil penelitian terhadap 18 responden Di Unit Pelaksana Teknis Daerah Puskesmas Hiliduho Tahun 2020, disimpulkan karakteristik responden umur 23- 25 sebanyak 8 orang $(44,4 \%)$, umur $26-29$ sebanyak 10 orang $(55,6 \%)$. Karakteristik responden berdasarkan jenis kelamin laki-laki sejumlah 5 orang $(27,8 \%)$, dan perempuan sejumlah 13 orang $(72,2 \%)$

Berdasarkan hasil kajian di atas, dapat disimpulkan bahwa pemberian neck calliet exercise dapat memberi efek yang bermakna terhadap penurunan nyeri leher hingga $38 \%$. Berdasarkan kesimpulan tersebut mengandung implikasi bahwa metode neck calliet exercise dapat dipertimbangkan dan dipilih untuk diterapkan dalam mengatasi nyeri leher pasien dengan memperhatikan kembali problematik fisioterapi, tujuan, dan prosedur pelaksanaan terapi yang tepat sehingga mendapatkan hasil terapi yang lebih maksimal.

\section{Saran}

6.1 Hasil yang diperolah dalam penelitian ini menunjukkan bahwa calliet exercise dapat mengurangi 
nyeri leher, namun perlu dilakukan penelitian lebih lanjut dengan jumlah respoden yang lebih banyak agar memperoleh tingkat efektifitas yang lebih baik.

6.2 Bagi peneliti selanjutnya agar dapat mengontrol pekerjaan responden yang dapat memperburuk keluhan, serta mengontrol setiap posisi kerja seorang sesuai dengan ergonomi.

\section{DAFTAR PUSTAKA}

Binarfika, M. N., Martiana, T. 2014. "Analisis tingkat resiko musculoscletal disordes (MSDs) dengan rappid upper limb assesment (RULA) dan karakteristik individu terhadap keluhan MSDs." The Indonesian Journal of Occupational Safety and Health.3 (2): 160-169

Cailliet, R. 2014. Neck and Arm Pain. Phyladelpia: F. A. DavisCompany.

Dharmajaya, Ridha. 2017. "Arsberet Kobenhavns Univ Med Hist Mus Spondylosis Cervicalis. "

Haryatno, Pajar dan Heru Purbo Kuntono, 2016. "Pengaruh Pemberian Tens Dan Myofascial Release Terhadap Penurunan Nyeri Leher Mekanik." Jurnal Terpadu Ilmu Kesehatan 5(2): 182-88.

Hidayat., 2011. "Metode Penelitian Keperawatan Dan Teknik Analisis Data". Jakarta :Salemba Medika.

Howard, N. et al., 2016. Work Related Musculoskeletal Disorders (WMSDs) in Washinton State Services, Safety and Health Assessment and Research for Prevention (SHARP) Program. Washington

Juliastuti, 2017. "Perbedaan Pengaruh Pemberian Auto Stretching Dan Kinesio Taping Terhadap Penurunan Nyeri Pada Sindroma Nyeri." 5.
Kusuma, $H$. dan Trisnowiyanto B., 2017. "Pengaruh Cailliet Dan Mc. Kenzie Neck Latihan Dalam Mengurangi Rasa Sakit Di Siklus Miofacial." Departemen Fisioterapi Politeknik Kesehatan Kementerian Kesehatan Republik Indonesia.

Nadhifah, Naurah. Irianto.dan A Besse Ahsaniyah. 2019. "Nusantara Medical Science Journal." : 7-13.

Notoatmodjo S., 2010. Metodelogi Penelitian Kesehatan. Jakarta : Rineka Cipta.

Nursalam, 2010.Variabel Dan Operasional Variabel.

Prianthara, I Made Dhita, I Made Niko Winaya dan I Made Muliarta, 2014. "Kombinasi Contract Relax Stretching Dan Infrared Terhadap Penurunan Nyeri Myofascial Pain Syndrome Otot Upper Trapezius Pada Mahasiswa Fisioterapi Fakultas Kedokteran Universitas Udayana." Fisioterapi Fakultas Kedokteran Universitas Udayana.

Riadho, Eliza dan Wahyuddin, 2019. "Hubungan Posisi Kerja Statis Terhadap Timbulnya Pendidikan Dan Kebudayaan Kota Jambi.". Fakultas Fisioterapi, Universitas Esa Unggul, and Kebon Jeruk.

Samara, Diana, 2017. Nyeri Muskuloskeletal Pada Leher Pekerja Dengan Posisi Pekerjaan Yang Statis. Vol. 26 (No.3) 137142.

Sastroasmoro, Harun, 2014. DasarDasar Metodelogi Penelitian Klinis.Edisi 5

Sekaaram, Vimalavarati, dan Luh Seri Ani. 2017. "Prevalensi Musculoskeletal Disorders ( MSDs ) Pada Pengemudi Angkutan Umum Di Terminal Mengwi, Kabupaten Badung-Bali." 8(2): 118-24.

Silvia, Nelmi, dan Indah Suci Widyahening, 2017. "Efektivitas Latihan Leher Dan Bahu Dalam 
Mengurangi Nyeri Leher Dan Bahu Pada Pekerja Kantor Dengan Komputer: Laporan Kasus Berbasis Bukti." : 592-98.

Soumya Bangalore Anandarao and Lakshmi Thimmaraju, (2014). Gender differences in cardiovascular response toupper limb isometric exercises. International Journal of Research in Health Sciences. 2(2). 23217251

Sudaryanto. $2015 . \quad$ "Biomekanik Vetebra." Vol 2 (no.3) 1-21

Tarwaka, $2016 . \quad$ "Dasar-dasar Keselamatan Kerja Serta Pencegahan Kecelakaan di Tempat Kerja. " Surakarta: Harapan Press

Syamsul, Ikhsan Dermawan. 2018. Pengaruh Muscle Energy Techniq (Met) Terhadap Perubahan Fungsional Cervical Pada Penderita Non-Spesific Neck Pain Di Rsud Haji.Global Health Science Volume 3 (No. 2) 106-112.

U.S Bureau of Labor Statistics, 2017. Survey of Occupational Injuries \& Illnesses Charts Package

Wahyuningsih, Ni Wayan, Nila Wahyuni dan Luh Made Indah Sri Handari Adiputra Wahyuni, 2018. Efektivitas Mulligan Mobilization Dan Infrared Dengan Myofascial Release Technique Dan Infrared Terhadap Peningkatan Lingkup Gerak Sendi Nyeri Leher Non Spesifik.

Wibaya, Made Bisma, I Made Niko Winaya dan I.G.N. Dedi Silakarma, 2019. "Kombinasi Masase Lebih Baik Dibandingkan Kontraksi Isometrik Pada Intervensi Mwd, Tens Dalam Penurunan Nyeri Pada Kasus Spondylosis Massage Combination Better Than Isometric Contraction At Intervention Of Mwd, Tens In Decrease Of Pain At Case Of Spondyl."
Widodo A., 2011. "Penambahan Ischemic Pressure, Sustained Stretching, Dan Treatment of Myofacial Pain. "A Literature Review. Volume 4(n0.2).

Yudiyanta, Novita Khoirunnisa, Ratih Wahyu Novita Nari. 2015. "Assessment Nyeri." Departement Neurologi, Fakultas Kedokteran Universitas Gadjah Mada, Yogyakarta, Indonesia 42(3): 21434. 